\title{
The Sound of Music: Transforming Medical Students into Reflective Practitioners
}

\author{
Marco Aurelio Janaudis ${ }^{1}$, Michelle Fleming ${ }^{2}$, Pablo González Blasco ${ }^{1}$ \\ ${ }^{1}$ SOBRAMFA Medical Education and Humanism, Sao Paulo, Brazil \\ ${ }^{2}$ Stellenbosch University, Stellenbosch, South Africa \\ Email:marcojanaudis@sobramfa.com.br
}

Received April 26 $6^{\text {th }}$, 2013; revised May $28^{\text {th }}$, 2013; accepted June $4^{\text {th }}, 2013$

\begin{abstract}
Copyright ( $) 2013$ Marco Aurelio Janaudis et al. This is an open access article distributed under the Creative Commons Attribution License, which permits unrestricted use, distribution, and reproduction in any medium, provided the original work is properly cited.
\end{abstract}

\begin{abstract}
There is a growing focus on the introduction of courses in humanities in medical education. Music is not a widely-used tool in medical education. It has unique features that make it an excellent educational resource for the possibility to express emotions. Within minutes, topics of interest in learning medicine, such as loss, compassion, sorrow, and solidarity can be identified and used in pedagogical processes. Music - like other art forms - can deal with the emotional universe of the student. Promoting a reflective attitude within an academic discipline requires the creation of space to make it formal. The Public Health Department of Jundiai Medical School (Sao Paulo, Brazil) offers a special course on family medicine core values, led by a SOBRAMFA Medical Education \& Humanism faculty member. The process of understanding a student's experience has allowed for the unveiling of a phenomenon that encompasses the student's inner world as he/she attends to his/her medical training. The music is played on the outside resonates with the story and emotions of the student. Students realize that the pace imposed by the medical school does not allow them to reflect on either their own lives or their formation. The musical experience allows students to hear their feelings and share them with the professor and peers. They are surprised by memories and feelings that surface that they were unaware of or could not remember. These feelings are presented in themes that organize the affective experience of students, mobilized by the music. Several themes have emerged, such as the search for the self; family; vocational doubts; relationships with peers, professors, and patients. The findings of the experience of the music spectrum come in, offering numerous prospects for development in the context of medical education, as noted in the themes that emerged. As the basic experience we have of the world is emotional, the music - this form of human knowledge of affective tone-also becomes educational force, because the teaching process is not limited to transmission of content. Instead, more importantly, it implies that the teacher in development processes of meaning and significance enable the learner to reflect and transform the everyday practice, especially in medicine, where the interpersonal relationship is the basis for the full realization of future professional action.
\end{abstract}

Keywords: Medical Student; Music; Humanism; Qualitative Research

\section{The Strength of the Songs}

Current medical practice is challenged by a highly technical and rapidly-changing environment that requires the professional to be adaptive and proficient while maintaining a caring, humanistic approach with patients. Such a balance, however, can be challenging for students to maintain and for educators to promote. Emerging technology tends to monopolize student attention and learning efforts, often at the expense of other important aspects of medicine (Calman, 1988; Schellenberg, 2001).

Humanism is a critical trait for developing future physicians who are committed to understanding and caring for their patients. Educators must provide ways for their students to reflect on the human dimension of doctoring and to foster development of critical-thinking skills (Blasco, 2001).

There is a growing focus on the introduction of courses in the humanities in medical education. The humanities are educa- tional resources for developing future physicians' humanism. Although literature, films, and poetry are often used to teach humanism, the educational possibilities of music have been less explored and rarely incorporated into a medical curriculum (Newell, 2003).

Music, like other art forms, can deal with the emotional universe of the student. Promoting a reflective attitude within an academic discipline requires the creation of space to make it formal (Janaudis, 2011). Out of all the arts, music probably has the strongest connection to human emotions. It has unique features which, while present singly in other artistic media, are combined in music. Unlike literature, music's emotive power is not necessarily dependent on language. Themes such as compassion and human dignity, as well as sadness and loss, are commonly explored in music, and weighty topics are often distilled into a few minutes in songs (Newell, 2003).

Finally, in contrast to the other arts, music teaches us how to listen. It is the perfect medium to learn how to listen not only to 
a patient's words but also to what lies behind those words by noticing cadence, volume, inflection, and tone (Newell, 2003).

\section{Describing the Scenario and the Musical Learning Experience}

The Public Health Department of Jundiai Medical School (Sao Paulo, Brazil) offers a special course on family medicine core values led by a SOBRAMFA Medical Education \& Humanism faculty member. It is a required clerkship for final year medical students, divided into small groups (15 students in each group), taking up a total of one day a week and lasting for nine weeks. This special course started four years ago, and 300 students have been involved so far.

The teaching format consists of two half day sessions each week. In one session, students see patients, and in the other, they have discussions regarding those values required for excellence in doctoring.

Incorporation of music arose organically when, one day during the first session of the course, a faculty member played a song that he realized could clarify some perspectives about the doctor-patient relationship. Students were surprised, and the ensuing discussion was particularly insightful. From that day on, music was often incorporated by the teacher and by the students themselves to enlighten their own reflections. They decided to integrate "the sound of music" into the teaching scenarios.

The musical learning experience has been running for the past four years. Some songs have been identified as useful resources for evoking attitudes about daily behavior, feelings and values (love, compassion, jealousy, empathy, forgiveness and revenge, understanding, communication), and they stimulate self-examination and disclosure of emotional responses. The songs act as triggers to foster discussion among learners because they identify with characters in the songs and use them to represent their own reality. Through the discussion, the participants give feedback on the songs and generate new themes for discussion, as well as suggesting other songs to use. Some of the songs are listed in Table $\mathbf{1}$.

In the past, some student groups have been asked to write about their experiences at the end of the special course. Some students who attended the course agreed to participate in out- lining a brief research project designed in a qualitative manner, through a group discussion and interviews. The interviews were taped, transcribed and then interpreted according to the hermeneutic perspective (Janaudis, 2011).

\section{Students Feedback: "I See the Light!", “I Gotta Feeling.”}

Students talked about many facets of the experience, including how it affected their perspectives on culture, fear, expectations about the future, and balancing work with family. There was much more than medicine, there was "life”. Songs led students to be emotionally open and disclose their feelings. Some feedback about the unique opportunity for emotional openness was as follows:

"In this experience, we were able to discuss issues we can't talk about during medical instruction, since there is no time, no room for that."

"The experience was very positive but at the same time leaves me quite sad: I realize how much I was able to think, reflect on these things, and now it sounds like I lost all that since I began medical school."

"The experience was a great surprise. We learned more than just the subject, we learned life manners. We started to look at each other like friends, not competitors."

The music-related teaching experience also fostered students' reflections about themselves, and their future professional roles:

"There is nothing more natural than music; art imitates life, correct? What happens today is that we don't have time in our lives, and our eyes remain too tired to see. So we forget a sense for details. Reflection with music helped us to understand: there were the lyrics, its poetry, music. All related to our own life; music gives us the opportunity to reflect a bit on who we are."

"Before entering the medical school, I used to reflect a lot. With this experience, I got back that wonderful feeling. I realized that 'medicine' was taking the main part of my life, and I had no time to reflect. That's a contradiction: good doctors need to be reflective."

An interesting situation arose with one group. Although the students build their small groups based on their preferences for

Table 1.

Some songs used in our educational experience with medical students.

\begin{tabular}{ccc}
\hline SONG & SINGER & PLAY THE SONG \\
\hline Suspicious Minds & Elvis Presley & http://www.youtube.com/watch?v=hohl44WZUWg\&feature=related \\
One & Metallica & http://www.youtube.com/watch?v=JDbQ53Q0tyM\&feature=related \\
The News & ack Jonhson & http://www.youtube.com/watch?v=0HhrjJxnLyo\&feature=related \\
Nos Bailes da Vida & Milton Nascimento & http://letras.terra.com.br/milton-nascimento/47438/ \\
Bola de Meia, Bola de Gude & Milton Nascimento & http://letras.terra.com.br/milton-nascimento/102443/ \\
Alma & Zélia Duncan & http://letras.terra.com.br/zelia-duncan/43887/ \\
Estrada Nova & Oswaldo Montenegro & http://letras.terra.com.br/oswaldo-montenegro/189353/ \\
Ciranda da Bailarina & Adriana Calcanhoto & http://letras.terra.com.br/adriana-calcanhotto/102206/ \\
La Bilirrubina & Juan Luiz Guerra & http://letras.terra.com.br/juan-luis-guerra/163411/ \\
\hline
\end{tabular}


facilitating team work, the natural fatigue in addition to the stressful environment of the previous medical school year erodes some relationships. Students often appear overwhelmed and can hardly talk among themselves without arguing. On the first day of the special session, however, they found themselves in a welcoming environment. The teacher did not start talking about public health issues as they were expecting but instead asked each student to introduce the colleague occupying the next seat. This exercise demonstrated to the students that they needed to understand each person to be able to understand the community. They disclosed their dilemmas, motivations, and expectations and realized (based on an Elvis song) that they could not go on together "with suspicious minds". They were then ready to immerse themselves in family medicine principles and see their patients in the community. They grasped the bottom line of what family medicine is all about: to understand ourselves in order to be able to understand our patients.

The last assignment was an amazing performance by the student group of the song "I Gotta Feeling" (from the Black Eyed Peas) as a tribute to our healing clerkship. It started as a joke, inspired by Oprah. During The Oprah Show's 24th season kickoff party, the Harpo staff and more than 20,000 people pulled off a massive surprise for the unsuspecting talk-show host. The entire crowd performed a choreographed piece to the Black Eyed Peas song. Award-winning director Michael Gracey says the interaction between the Black Eyed Peas and the crowd is what made the Oprah flash mob so extraordinary.

A video of this flash mob performance was sent to the students as a "challenge", in the form of a joke, with the group being told that if they could recreate this performance, they would be excused from taking the final exam. The group worked together and copied the performance!

One question emerged from our experience with students in this special course: Is the student burnout we observe in the last years of medical school responsible for the lack of humanity in their practice? These student quotes address that question:

"Today this song became our song. When we started to dehumanize, we just listened to it and became humans again."

"We opened that way because of the welcoming environment, the lack of hierarchy, and the way we were treated by our superiors: as colleagues. For the first time, we were appreciated as individuals and not for what we produce."

\section{Understanding the Learning Process: Without Suspicious Mind(s) (James, 1969)}

The process of understanding the students' experience allowed for the unveiling of a phenomenon that encompasses their inner world as they attend to their medical training. The music played on the outside resonates with the story and emotions of the student. The student realizes that the pace imposed by the medical school does not allow him to reflect, whether on his own life or in his formation. The music experience allows students to hear their feelings and share them with the professor and peers. They are surprised by memories and feelings that surface that they were unaware of or that they could not remember. These feelings are presented in themes that organize the affective experience of the student, mobilized by the music. Several themes emerged as well as the search for self: family; death; vocational doubts; relationships with peers, professors, and patients.

Education is much more than simple training, which refers only to the acquisition of specific skills. To educate implies the ability to drive one's students to reach their potential. Fostering human skills is a major aim of medical education because these skills are essential for clinical competence and professional development. The use of art forms in medical education helps to engage students, trigger reflection and empathy, and increase cultural awareness and sensitivity.

Music has several characteristics that make it particularly suitable for humanistic training in medicine, with the potential for enhancing caring and compassion in students. Exposing students to songs-followed by faculty-facilitated open discussion-stresses emerging topics, stimulates reflection on the personal and professional attitudes and values of medical students, and proves to be a useful and enjoyable way of teaching.

Music has some practical advantages that make it an easy tool for instructing students in humanism. It can be played in a group setting, making it ideal for group participation. Music is also portable and retains its effect, even in small settings. As noted above, the emotional power of a piece of music is independent of its length. Some of the most powerful recordings ever made (for example Queen's “We Will Rock You”) are three minutes long. In addition, music is probably one of most physical of arts, often provoking reactions such as toe-tapping and dancing, making it easily and readily accepted by busy residents and students (Blasco, 2005).

Music is a universal language that young students easily assimilate. In addition, it can be a stimulus for personal and professional development because it touches uniquely on emotions. Emotions play a specific role in learning attitudes and behavior, and educators cannot afford to ignore the affective domain. In life, the most important attitudes, values, and actions are taught through role modeling and example, a process that acts directly on a learner's emotions. Because feelings exist before concepts, the affective path is a critical short-cut to the rational process of learning. Although technical knowledge and skills can be acquired through training with little in the way of a reflective process, it is impossible to refine attitudes, acquire virtues, and incorporate values without reflection.

\section{The Bottom Line: Sing of Good Things Not Bad, Sing for You and Me (The Carpenters, 1973)}

Engaging learners emotionally and promoting reflection about events they see and hear are essential elements for provoking useful discussions about values and ethics. Teaching in the affective domain (i.e., attitudes and beliefs) requires innovative strategies that meet learners' needs, and techniques that are current and fit the students' culture. It makes sense, therefore, to use music to teach emotionally-based subjects such as the humanities and ethics (Blasco, 2005; Janaudis, 2011).

The results arise from the students' own assessments of the course. They have had room to reflect on their feelings, expectations, and fears; even though those matters are usually in their minds, they have never before found such a comfortable environment for disclosing them. They share without constraint their uncertainty, emotions, and doubts, and they picture their future as doctors and as human beings. Ultimately, they enrich themselves through self-knowledge.

The findings of the experience of the music spectrum come in, offering numerous prospects for development in the context of medical education, as noted in the themes that emerged. As the basic experience we have of the world is emotional, the 
music - this form of human knowledge of affective tone-also becomes an educational force, because the process of teaching is not limited to transmission of content. More importantly, it implies that the teacher in development processes of meaning and significance enable the learner to reflect and transform the everyday practice, especially in medicine, where the interpersonal relationship is the basis for the full realization of future professional action.

\section{REFERENCES}

Blasco, P. G. (2001). Literature and movies for medical students. Family Medicine, 33, 426-428.

Blasco, P. G., Moreto, G., \& Levites, M. R. (2005). Teaching humanities through opera: Leading medical students to reflective attitudes. Family Medicine, 37, 18-20.
Calman, K. C., Downey, R. S., Duthie, M., et al. (1988). Literature and medicine: A short course for medical students. Medical Education, 22, 265-269. doi:10.1111/j.1365-2923.1988.tb00752.x

James, M. (1969). Suspicious Minds, song by Elvis Presley.

Janaudis, M. A. (2011) A música como instrumento de reflexão para o estudante de Medicina [tese]. São Paulo: Faculdade de Medicina. URL (last checked 14 April 2013).

http://www.teses.usp.br/teses/disponiveis/5/5169/tde-20052011-1753 $37 /$

Newell, G. C., \& Hanes, D. J. (2003). Listening to music: The case for its use in teaching medical humanism. Academic Medicine, 78, 714719. doi:10.1097/00001888-200307000-00012

Schellenberg, E. G. (2001) Music and nonmusical abilities. Annals of the New York Academy of Sciences, 930, 355-371. doi:10.1111/j.1749-6632.2001.tb05744.x

The Carpenters (1973) Sing, song by Carpenters. 